\title{
An Estimate of Average Cost of Hypertension and its catastrophic effect on the people living with hypertension: Patients' perception from two Hospitals in Abuja, Nigeria
}

\author{
Idris Abubakar'1, Obansa, S.A.J ${ }^{2}$ \\ ${ }^{1} \mathrm{PhD}$ economics, Department of Economics, Faculty of the Social Science University of Abuja, Federal, Capital Territory, Abuja-Nigeria. \\ Email: idrisbakr@yahoo.com \\ ${ }^{2}$ Professor of Economics, Department of Economics, Faculty of Social Science University of Abuja, Federal, Capital Territory, Abuja- \\ Nigeria. email: jobansa@yahoo.co.uk
}

Keywords: Hypertension, Catastrophic spending, Personal spending, Least income, Urban dwellers, Intervention scheme.

\begin{abstract}
Purpose of the study: The study was motivated by the high prevalence of hypertension and its associated costs of financing drugs to treating the disease. Hypertension has become a source of worry to the sufferers and caregivers, given its direct and indirect cost implications. The study specifically estimated the direct average cost of treating hypertension and verified its catastrophic effect on the sufferers in Nigeria.
\end{abstract}

Methodology: To achieve the objective, the study undertook the review of related literature on the burden of hypertension. It utilized the primary method of data collection by administering structured questionnaires to the target respondents in the University of Abuja Teaching Hospital and National Hospital, Abuja, Nigeria. Data were descriptively analysed using frequency and percentage with the aid of SPSS version 22.

Main findings: The result revealed that the average annual cost attributable to hypertension treatment is N145, 086.12 per patient. The study documented that 191(82 percent) patients undertook personal health spending. Hypertension financing was discovered to be catastrophic among 30.5 percent of the least income patients. Therefore, it concluded that the average cost of treating hypertension was high among urban dwellers and catastrophic among the least earners.

Res Research limitations/implications: The findings will be relevant for the policy framework for government relating to healthcare financing and the establishment of intervention schemes that will alleviate the burdens associated with hypertension among the sufferers. Health planners and administrators will immensely benefit from the study as the study revealed the knowledge of treating hypertension for planning purposes and reference points for both researchers and academics.

Novelty/Originality of this study: Knowledge relating to the direct cost of treating hypertension annually for intervention purposes is limited. Therefore, to touch lightly upon this, the study attempted an estimation of the average annual direct cost of treating hypertension and its associated burdens to the sufferers through a survey investigation. Findings, therefore, will advance the existing knowledge on the burden of hypertension and the policy of healthcare interventions.

\section{INTRODUCTION}

The degree of prevalence and morbidity resulting from hypertension and its complications like stroke, cardiovascular and ischemic heart attack are enormous and rising every day (Gaziano, Bitton, Anand \& Weinstein, 2009; Ogah et al., 2012; Kengne, Mchiza, Amoah \& Mbanya, 2013). The treatment of hypertension is accompanied with direct and indirect costs, which is very high. In the case of complications that result in stroke, it demands the assistance of the caregiver to support the patients both physically and financially. This posed a substantial financial burden to care-givers (assistants). Indeed, the level of high private health spending undertaking by patients in the bid to adhere to drug prescriptions and to curtail the complications of hypertension is alarming and has an adverse effect on the income of the individual(s) affected. Also, the savings and investment potentials of individual households affected by hypertension are likely to be depleted, given the burden of hypertension on households' income. In aggregation, the pandemic impact of hypertension as one of the noncommunicable diseases (NDCs) has been established to be a threat to sustainable economic growth and development of both developed and developing countries (Bloom et al., 2013). This is because the burden of hypertension may affect the ability of

Corresponding Author: ${ }^{1}$ idrisbakr@yahoo.com 
individuals to save and creates other costs that affect the income of households. The level of investments and accumulation of capital is therefore affected. This is consequently impoverishing both individuals and reducing the economic growth of most nations.

The prevalence of hypertension and related implications in Nigeria is disturbing (Ogah, et al., 2012) though the proportion of people affected by hypertension and hospitalization may be reduced owing to continuous treatments. Though this involves high spending. It is also disturbing to our conviction that there is the dearth of information relating to the number of deaths resulting from hypertension, the prevalence, and its degree of complications in most societies, especially where there is no or inadequate health records system. Most people may not be even aware that they are hypertensive owing to their attitudes toward medical check-ups to know their health status. Those who are aware may prefer to seek the attention of the pharmacists to get drugs across the counter, which affects records /documentation of hypertensive households in Nigeria. This makes it difficult to appreciate the economic consequences of hypertension. Though, few studies have investigated the prevalence and extent to which the burden of hypertension has affected the households in Nigeria with little or no effort to estimate the average cost of treating and controlling high blood elevation most especially in the urban city in the north-central of Nigeria (Ogah et al. 2012). The recent study of Okubadejo, Ozo, and Agabi (2019) also dwell on the prevalence of hypertension and blood pressure profile among adults in Lagos, the western part of Nigeria, with no consideration to the cost of the disease to the vulnerable persons. Arising from the above, this study attempted to estimate the direct cost of treating hypertension and its catastrophic effect on the sufferers in Nigeria with empirical evidence from two hospitals (National Hospital and University of Abuja Teaching hospital) all in the Federal Capital Territory (FCT), Abuja, Nigeria.

\section{LITERATURE REVIEW}

It is estimated that over 20 percent of the world's adults' population has hypertension when hypertension is defined in recent times as elevated high blood pressure (HBP) of 140/90 mm Hg and above (World Health Organization, 2013). There is a dramatic change in the occurrence of HBP among adults of less than or equal to 60 years old. Stressing on the prevalence of hypertension and risk factor to other diseases like heart, brain, kidney, and other diseases, WHO (2019) estimated that about 1.13 billion people have hypertension from which two-thirds are living in low- and middle - income countries. The earlier study of Abegunde and Stanciole (2006) documented that about 50 percent of the population of productive age is established to have hypertension, thereby translating to approximately one billion individuals worldwide who have hypertension.

In Nigeria, it was discovered by the 1991 national survey on non-communicable diseases that about 4.33 million Nigerians over 15 years of age are hypertensive, out of a population of 88.5 million as at 19991 Nigeria population. The federal ministry of health Federal Ministry of Health, (1991) national survey showed that the prevalence of hypertension rises with age, and its prevalence proportion among males and females population was 11.1 percent and 11.2 percent, respectively. Therefore, the overall of prevalence as at 1991 based on the federal ministry of health survey was 11.2 percent. However, given the shift in cut-off point to $140 / 90 \mathrm{mmHg}$, the prevalence of hypertension is now higher by 20 percent in the population. The high morbidity and mortality rate, low life expectancy, disability and low productivity due to hypertension are becoming prevalent in Nigeria (Lambo, 2007; Unadike, Essien, Akpan, Peters \& Essien, 2013; Kengne et al., 2013; Eze \& Kalu , 2014 ; Odili \& Abatta, 2015). Therefore, the burden of direct and indirect costs of hypertension to patients and their caregivers are likely to have a negative effect on their income and performance of the overall economy. This may be due to high costs associated with complicated conditions that reduce national output in both developed and low middle-income countries. Emphasizing on the burden of hypertension, Dzau and Celynne (2019) suggested that to ease the future burden of the disease; there is a need to stress on convergent of digital data, biotechnology, and biomedical sciences coupled with their implementation in healthcare delivery.

Evidence of catastrophic burdens associated with non-communicable diseases to the economies of many nations can be gleaned from studies (Bloom et al. 2013; Jha, Nugent, Varguet, Bloom, \& Hum, 2013; Webb \& Conrad, 2012). To estimate the cost of blood pressure control in Nigeria, the study of Ilesanmi, Ige, and Adebiyi (2012), employed a chart review of the cross-sectional survey of 250 rural patients with primary hypertension at a regional hospital in Southwest Nigeria and discovered N1,440 the mean cost of monthly treatment of hypertension in the region. A recent study of Zhang, Wang, and Sun (2020) submitted that hypertension is a public health challenge. Their study employed logistic regression technique for a randomized block of 400 patients in six selected provinces in China, suggested that financial incentive plays a vital role in making patients adhering to the treatment thereby controlling the disease and eases the burden of the disease to those suffers.

Bakare et al. (2016) employed a survey method to examine antihypertensive use, prescription patterns, and cost of medications in a teaching hospital in Lagos, Nigeria. Also discovered that the most prescribed antihypertensive drugs were diuretics with 64 percent followed by beta-blockers with 63 percent; calcium channel blockers 53, while the least prescribed drugs were alpha-blockers, was 9 percent. Their study revealed that the average cost of drugs per individual in treating hypertension in a month was N2,045. To estimate annual total medical expenditures associated with hypertension by diabetes status in the United States (US), Wang, Zhou, Zhuo, and Zhang (2017) utilized the two-part econometric and generalized linear model to estimate data on medical expenditure panel survey and documented that hypertension patients with diabetes 
have increased medical expenditure by $\$ 2,753$ more than nondiabetes hypertension patients. Kirkland et al. (2018) national survey on the trends on healthcare expenditures for patients with hypertension in the United States (US) revealed that unadjusted mean annual medical expenditure attributable to patients with hypertension was $\$ 9,089$ and concluded that relatively individual with hypertension spent about $\$, 2000$ higher than non-hypertensive patients annually. This indicates potential economic burdens to these living with hypertension.

Estimating the cost of hypertension and associated factors in Ethiopia, Adane, Atanfu, and Aschalew (2020) undertook a survey at the University of Gondar Comprehensive specialized hospital in the Northwest of Ethiopia. They analyzed 442 adult hypertensive patients' responses and discovered that the cost of treating hypertension per individual patients was US\$91.72 per annum. The study revealed that medical cost constituted the high cost among the direct cost components of treating hypertension and recorded socioeconomic status and government employment as major significant factors that are associated with the high cost of managing and treating hypertension in the region. This is in line with an earlier study of Oyando et al. (2019) that utilized a cross-sectional survey to examine the patient costs associated with obtaining care for hypertension in public health care facilities in Kenya. Their study showed that the overall mean annual direct cost of treating hypertension to patients in Kenya is US\$304.8 while the indirect cost was US\$171.7. The study further revealed the catastrophic cost effect of treating hypertension, which was put at 43.3 percent in Kenya. However, there is an argument that the cost of hypertension, most especially catastrophic scenarios, can be minimized through adherence to medications and self-management. To substantiate this, Li and Hesketh (2020) employed a systematic and meta-analysis approach to investigate the effectiveness of self-management of hypertension among adults who use mobile health. Five electronic databases, which were inclusive of the snowballing method was systematically utilized to gather 24 published related studies from the period between January 2010 and September 2019, and their findings revealed that 16 out of the 24 reviews reported better medication adherence and behavioral change while 8 showed no significant change. This led support to the effectiveness of adherence to medication and self-management of hypertension using mobile health care to reducing associated direct cost, thereby avoiding catastrophic health effects.

\section{METHODOLOGY}

A survey method was conducted in two tertiary hospitals (National hospital and University of Abuja Teaching Hospital) in the federal capital territory, Abuja. The instrument of questionnaires was administered to patients who visited the hospitals from February to March 2018. Information relating to the cost of drugs used, diagnostic, consultations, and transportation constituting direct cost was obtained. The sample size of 233.99 for the study was derived from the morbidity population of patients living with the disease as in 2016, which was estimated to be 607 hypertensive patients attending the National Hospital. This is assumed to be a finite number, which represents the entire population of the study. Given this, we are ninety-five (95) per cent confident that the percentage has been estimated to be within + or -5 per cent of the true value. This means that the allowable error accommodated in this study is five (5) per cent or 0.05 . The formula, based on the assumption of the finite population was used in line with $\underline{\text { Krejcie and Morgan (1970) }}$ reported in (Kado, Bala, \& Dandajeh, 2016).

The finite population formula is stated thus:

Where

$$
n=\frac{Z^{2} * N^{*} P *(1-P)}{M E^{2} *(N-1)+\left(X^{2} * P^{*}(1-P)\right.}
$$

$\mathrm{n}=$ expected sample size

$\mathrm{Z}^{2}=$ the confidence level

$\mathrm{ME}^{2}=$ the desired margin of error

$\mathrm{N}=$ population size

$\mathrm{P}=\quad$ proportion of the population (assumed to be 0.50 since this would provide the maximum sample size.

Where:

$\mathrm{Z}^{2}=1.96$ as per the table of the area under the normal curve for the given confidence level of $95 \%$

$\mathrm{ME}^{2}=0.05$ since the estimate should be within $5 \%$ of the true value

$\mathrm{P}=0.50$ as we want the most conservative sample size of the population

Note: $\mathrm{N}$ is the prevalence population of morbidity resulting from hypertension, which is 607 based on the year 2016 morbidity data from the National Hospital health records.

Employing the formula in the case of finite population, we have thus:

$$
\begin{array}{ll}
\mathrm{n}= & \frac{\mathrm{Z}^{2} * \mathrm{~N} * \mathrm{P} *(1-\mathrm{P})}{\mathrm{ME}^{2}(\mathrm{~N}-1)+\left(\mathrm{Z}^{2} * \mathrm{P} *(1-\mathrm{P})\right.} \\
\mathrm{n}=\frac{(1.96)^{2} * 607 * 0.5(1-.5)}{0.05^{2} *(607-1)+\left(1.96^{2} * 0.5(1-.5)\right.} \\
\mathrm{n}=\frac{3.8025 * 607 * 0.25}{(0.0025 * 606)+3.8025 * 0.25}
\end{array}
$$




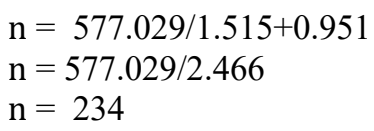

Therefore, the most conservative sample size needed in this study was approximately 234. Given the sample size determined for this study, and for non-response purposes, about 300 questionnaires were administered in the two hospitals. Out of the 300 questionnaires administered, 255 were returned. From the 255 returned, 22 were not completely filled, leaving about 233 for analysis. When subjected to the reliability test, a listwise exclusion of one (1) questionnaire was carried out by SPSS, and leaves 232 represented 99.4 percent valid cases for analysis. The coefficient of reliability, as documented by Ndiyo (2015), is given as (1- excluded questionnaire/valid cases for analysis) x $100=1 / 232 \times 100$ gave 99.57 percent indicating reliability instrument used in the study. Descriptive statistics comprises mean, percentage, and frequencies were calculated.

\subsection{Ethical Approval}

Prior to the administration of questionnaires, ethical approval was obtained from the ethical and research units of the two hospitals.

\subsection{Procedures for Quantification of Average Cost of Treating Hypertension in Abuja}

To quantify the average annual total cost an individual patient incurs to have their blood elevation control, the total cost of illness or diseases is regarded to be the summation of direct and indirect cost as stressed by Chao (2013). Therefore, information relating to direct costs associated with hypertension gathered from the instrument of questionnaires as provided by the respondents was utilized. This is supplemented with information obtained through interviews with the health practitioners. To obtain the average costs of treating hypertension, the study made three fundamental assumptions which are:

- There is no recognition of indirect cost because of the difficulties of the imputation of value to the indirect cost of illness without recourse to co-morbidity.

- Costs that falls within the common knowledge of the maintenance and cure of hypertension were focused.

- Costs that are associated with a chronic situation that may lead to brain hemorrhage and other complications were exempted due to their seldom nature and huge cost.

\section{RESULTS AND ANALYSIS}

The 255 participants were included in the study, and 232 valid cases were analysed. Of the 232 respondents, 118 (50.9 percent) are women, while 114 (49.1 percent) are men. Respondents age distributions are: 15 - 30 years 10 (4.3 per cent), 31-60 years 165 (70.8 percent) and $\geq 61$ years 57 (24.5 percent). Also, 30.5 percent, 16.7 percent, 18.9 percent, and 21.9 percent of the respondents reported annual earning of $<\mathrm{N} 180,000 ; \mathrm{N} 190,000$ to N490, 000; N500, 000 to N990, 000 and $>\mathrm{N} 1$ 000000 respectively.

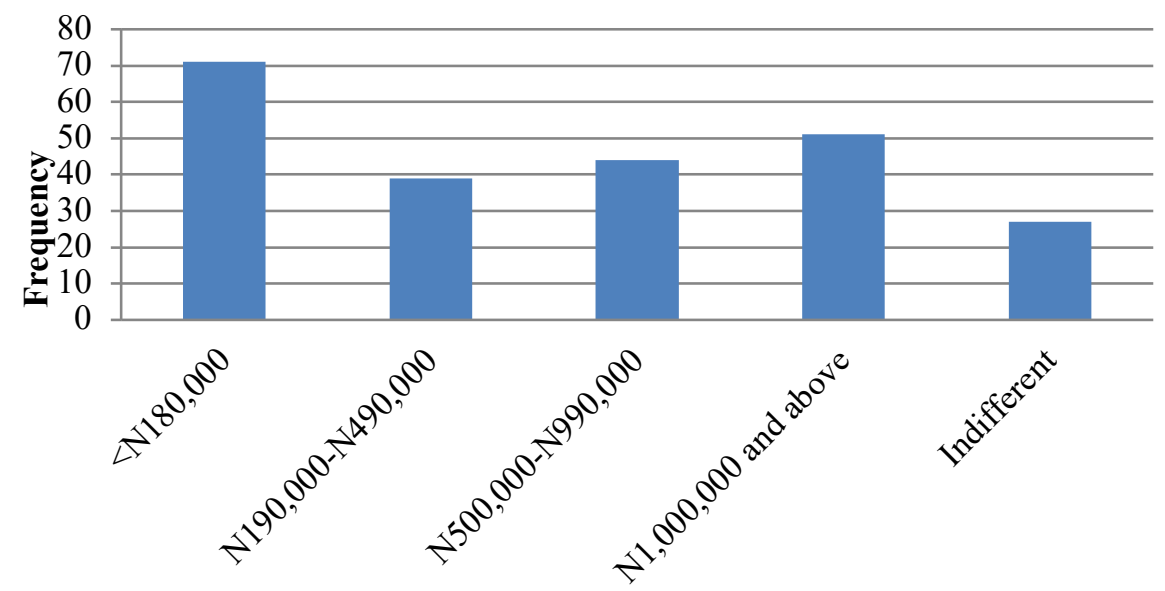

Figure 1: Distribution of Respondents' Estimated Annual Income

Source: Author's Field Survey, 2018. 
Figure 1 showed the distribution of the respondents' annual income, which estimated the income group of persons that suffered more the burden of hypertension. It was observed from the table that about 71 of the respondents which were 30.5 percent of the population, earn an income less than or equal to N180,000 per annum. Again, about 39 of the respondents, which constituted 16.7 percent of the population fell within the income bracket of N190, 000 to N490, 000 per annum. Besides, 44 of the respondents, which represent about 18.9 percent of the distribution, earn an income of between the ranges of N500, $000-\mathrm{N} 990,000$. In addition, about 51 of the respondents who were 21.9 percent of the population of study earn an income of about N1, 000,000 and above. The respondents who were indifferent or did not specify their earned income were 27 in number and represented about 11.6 percent of the population of the study. This indicated that the income group of $\leq 180,000$ (30.5 percent) per annum suffer more of hypertension than other income groups of the respondents as they constituted more numbers among the respondents of investigation in the study.

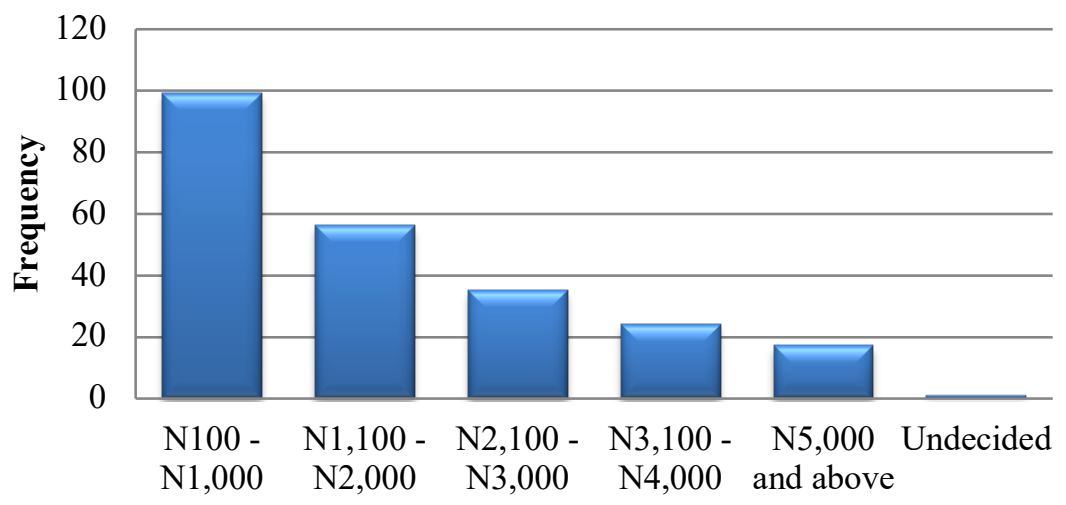

Figure 2: Distribution of Respondents Spending on Transport to Hospital each time of visit.

Source: Author's Field Survey, 2018.

Figure 2 denoted the percentage distribution of respondents' spending on transportation to the hospital each time of visit. To determine the extent of the burden to the sufferer, it was observed from figure 2 that 99 of the respondents, which constituted 42.5 percent of the population of the study, spent between N100 to N1, 000 on transportation each time of the visit to the hospital. On the other hand, 56 of the respondents, which represented 24 percent of the population of the study, spent between N1, 100 to N2, 000 on transportation each time of the visit to the hospital. Also, 35 of the respondents, which represented 15 percent of the population of the study, spent between N2, 100 to N3, 000. Equally, 24 respondents constituted about 10.3 percent of the population of the study, spent between N3, 100 to N4, 000 on transportation on each visit to the hospital.

Similarly, 17 respondents, which represented 7.3 percent of the population of the study, spent about N5, 000 and above. This group of respondents spent more on transportation each time they visited the hospital. Therefore, in the distribution, it was discovered that patients who spent between N100-N1,000 on transportation to the hospital are more. In contrast, those that spent N5,000 above are less, indicating that transportation as a component of direct cost varies among patients and constituted a minimum part of the direct costs of hypertension.

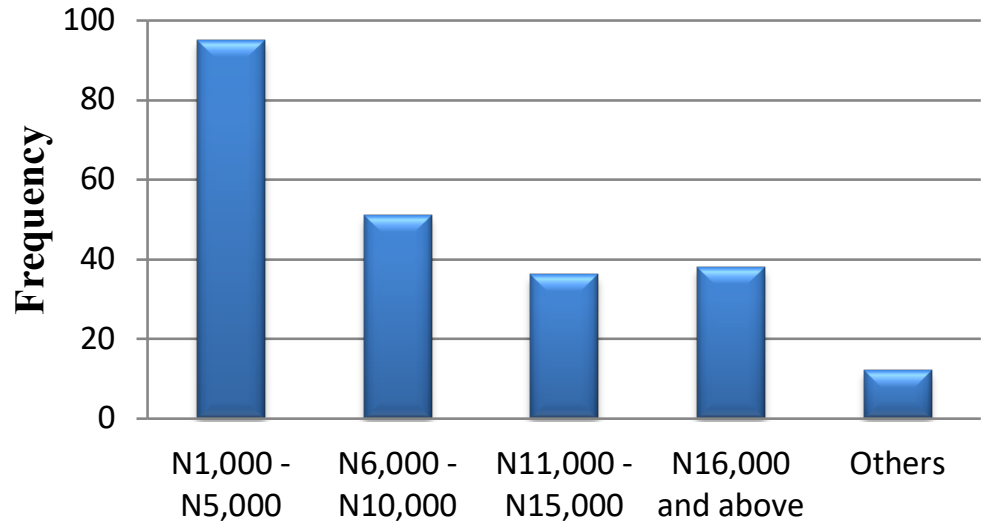

Figure 3: Distribution of Respondents' Monthly Spending on Hypertensive Drugs

Source: Author's Field Survey, 2018.

Figure 3 showed the frequency distribution of respondents' monthly spending on drugs. The figure documented that about 95 of the respondents (40.8 percent) spent between N1, 000 to N5, 000 monthly on drugs, while 51 of the respondents 
(21.9 percent) spent about N6, 000 to N10, 000 on drugs monthly. In the same vein, 36 respondents or 15.5 percent spent between N11, 000 to N15, 000 on drugs monthly. Again, 38 respondents, which represented 16.3 percent spent N16, 000, and above on drugs monthly. Other respondents who were not specific or do not have adequate knowledge of their spending on drugs regularly were 12, which represented about 5.2 percent of the population of the study. Figure 3 indicated that most patients spent between N1, 000 - N5, 000 while the least patients spent between N11,000 - N15,000 monthly on drugs.

Table 1 showed detailed computations of the average annual direct cost of the burden of hypertension incurred by individual patients in Nigeria as gleaned from the evidence from Federal Capital Territory, Abuja.

TABLE 1

Computation of Average Annual Spending Attributable to Hypertension per Individual

\begin{tabular}{|c|c|c|c|c|c|c|}
\hline $\begin{array}{l}\text { C1. } \\
\text { Average Unit Cost of } \\
\text { Drugs } \\
\text { (\#) }\end{array}$ & $\begin{array}{l}\text { C2. } \\
\text { Number of } \\
\text { Respondents }\end{array}$ & $\begin{array}{l}1 * 2=(\mathrm{C} 3) \\
\text { Total cost } \\
\text { of Drugs } \\
(\#)\end{array}$ & $\begin{array}{l}\text { C4. } \\
\text { Diagnosis } \\
\text { fee } \\
\text { (\#) }\end{array}$ & $\begin{array}{l}\text { C5. Consultation } \\
\text { Fee } \\
\text { (स) }\end{array}$ & $\begin{array}{l}\text { C6. } \\
\text { Average Transport } \\
\text { cost } \\
\text { (\#) }\end{array}$ & $\begin{array}{l}\text { C7. } \\
\text { Grand rotal } \\
\text { Average Annual } \\
\text { Spending } \\
\text { (A) }\end{array}$ \\
\hline 3000 & 95 & 285,000 & $20,000(231)$ & $808.20(4)$ & $550(99)=54,450$ & \\
\hline 8000 & 51 & 408,000 & & & $1550(56)=86,800$ & \\
\hline 13,000 & 36 & 468,000 & & & $2,550(35)=89,250$ & \\
\hline 18,000 & 38 & 684,000 & & & $5,450(17)=92,650$ & \\
\hline Total & 220 & $1,845,000$ & 462,000 & $3,232.80$ & 408,350 & \\
\hline $\begin{array}{r}\text { Average } \\
\text { Spending }\end{array}$ & & $\begin{array}{l}\mathrm{C} 3 \text { total / C2 } \\
\text { total }=8,386.36\end{array}$ & $\begin{array}{l}\text { C4 total } / 231= \\
20,000 / 12= \\
1667\end{array}$ & $\begin{array}{l}\text { C5 total } / 12= \\
269.40\end{array}$ & $\begin{array}{l}\text { C6 total } / 231 \\
=1,767.75\end{array}$ & $12,090.51$ \\
\hline $\begin{array}{l}\text { Total } \\
\text { Average Annual } \\
\text { Spending }\end{array}$ & & & & & $\mathrm{C} 7 * 12$ & $145,086.12$ \\
\hline
\end{tabular}

Source: Author's Field Survey /Computation, 2018.

The components of the attributable cost used in this study were: monthly spending on drugs, transportation cost to the hospital, consultation, and diagnosis fee. The attributable money spent was derived from the information provided by the respondents. It was observed from table 1 that individual patients spent a minimum average of $12,090.51$ monthly to manage hypertension. This translated to $\$ 145,086.12$ annual average expenditures on hypertension per hypertension patient. The total annual average was derived by taking the respective individual spending on drugs, and transportation cost vary among individual patients depending on the type of drugs and their locations. The diagnosis was taken as a fixed amount, which was paid once, and the consultation fee was regarded to be paid at least four times in a year as the time of visit for consultation annually. The average number of times of the visit to hospital owing to hypertension was limited to four times per annum as gathered from the respondents, but this vary when the health condition becomes complicated. The total cost was obtained by taking sum of the product of the 231 respondents' cost of consultation and diagnosis and the product of cost of drugs of 220 respondents who know the cost of their medications. Hypertension Patients with similar pattern of spending were grouped in the same class. Therefore, the average monthly hypertension spending by the individual patients as demonstrated in the table 1 were derived by summing the columns of the $7^{\text {th }}$ row which are $C 3+C 4+C 5+C 6=C 7$.

Where,

$\mathrm{C}=$ represent columns as stated in table 1 . Therefore, the total average annual individual spending on hypertension was obtained by multiplying the individual average monthly spending by 12 as presented in column seven $(\mathrm{C} 7)$ of the $8^{\text {th }}$ row in the table 1.To determine whether or not the individual spending on hypertension is a burden or not, the study further estimated the ratio of out-of pocket spending on hypertension to the income groups of the individual patients using data gathered from interview and questionnaires. This enabled the study established that spending on hypertension was catastrophic relative to income bracket of the sufferers.

\subsection{Determination of Catastrophic effect of hypertensive spending}

Catastrophic spending is defined as out-of-pocket spending for healthcare that exceeds a certain proportion of a household's income with the consequence that a household suffers the burden of disease (Ekman, 2007). The common thresholds used to determine that out-of- pocket spending is catastrophic are 10 percent of total income or 40 percent of nonfood income ( $\mathrm{Xu}$, Evans, Carrin, \& Aguilar-Rivera, 2005; Wagstaff \& Doorslaer, 2002). Also, a household was adjudged to have been impoverished when medical expenditure caused individual to fall below poverty line. Xu et al.(2005) measured catastrophic spending based on capacity to pay and used $40 \%$ as benchmark to which out-of-pocket spending on health may be regarded as being catastrophic. Wagstaff and Doorslaer (2002) calculated catastrophic spending as the percentage ratio of total out-of-pocket spending on health for household i ( $\mathrm{T}$ i) to total expenditure on food for household i (Xi)

That is $\mathrm{Ti} / \mathrm{Xi}$

Where

Please cite this article as: Abubakar, I., \& S.A.J, O. (2020). An Estimate of Average Cost of Hypertension and its catastrophic effect on the people living with hypertension: Patients' perception from two Hospitals in Abuja, Nigeria. International Journal of Social Sciences and Economic Review, 2(2), 1019. https://doi.org/10.36923/ijsser.v2i2.62 
$\mathrm{Ti}=$ total out-of-pocket spending on health

$\mathrm{Xi}=$ total income equal total expenditure less food expenditure).

In this study, $\mathrm{Xi}$ is defined as the total annual income of the patients without consideration to food expenditure. Given this, the study determines catastrophic health spending among hypertension patients as the ratio of average annual hypertension expenditures to annual income groups of the patients. This is calculated thus:

i. Catastrophic Spending (CS) of patients with income less than N180,000/annum $=\mathrm{Ti} / \mathrm{Xi} * 100=145,086.12 / 180,000 \times 100$ $=80.60$ percent.

The result indicates that patients in the income bracket of less than N180, 000 per annum spent about 80.6 percent of their annual income on the average which was greater than both 10 and 40 percents as the lower and upper thresholds of determining catastrophic health spending respectively. This implied that hypertension related expenditure is catastrophic to the least income respondents who consisted of the 30.5 percent of the respondents with annual average income of less than or equal to N180,000. The results demonstrated that the lower income earners who suffered from hypertension or blood pressure and undertook out-of-pocket spending to curtail the disease are not only more likely to experience significant burdened of hypertension but also likely to be impoverished by the disease. This occurred as more fraction of the individual patients' income is channeled to the management of hypertension.

ii. Catastrophic Spending (CS) of patients with average annual incomes group of N340,000 $=145,086.12 / 340,000 * 100=$ 42.67 percent.

This indicated that about 16.7 percent of this group spending on health was catastrophic given the CS which was greater than both thresholds of 10 percent and 40 percent. This lay bare that individual patients in this group are impoverished by their spending for managing hypertension. Therefore, the result indicated that income level of individual determines the degree of catastrophic health spending exposed to by patients.

iii. Catastrophic Spending (CS) of patients with average annual income of N745,000 $=145,086.12 / 745,000 * 100=19.47$ percent.

This shows that about 18.9 percent of the respondents as presented in table 1 undertook a catastrophic spending as CS of this income group was approximately 9.5 percent greater than the lower threshold but less than the higher benchmark of 40 percent. This showed that, the wealthier an individual the less likely for him or her to experience catastrophic spending thereby less likely for the patients to experience burden of disease that may lead to impoverishment.

iv. Catastrophic Spending (CS) of patients with the average annual income of N1,000,000 $=145,086.12 / 1,000,000=14.51$ percent.

This suggested that about 21.9 percent of the respondents have catastrophic spending of about 4.5 percent (i.e. 14.5 percent 10 percent) indicating that the higher the income of the patients, the lesser the likelihood to experience catastrophic spending and be impoverished by out-of-pocket spending. The result showed a mild effect of impoverishment resulted from hypertension spending among high income group of individual patients.

\subsection{Determination of the Level of enrollment in government intervention Scheme.}

Given the level of catastrophic spending individual patients were faced with, the study discovered that substantial number of the participants were not enrolled in government health intervention scheme like national health insurance scheme (NHIS). However, the findings also illustrated that those enrolled do not enjoy full coverage as depicted in figure 4.

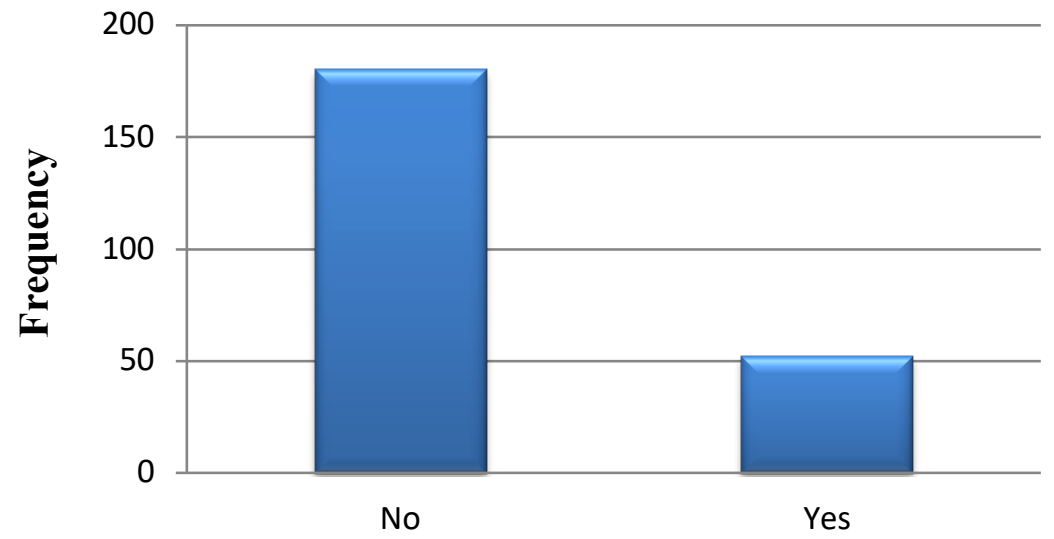


Figure 4: Frequency Distributions of Respondents Enrolled in any Government Intervention Programme in curtailing Hypertension

Source: Author's Field Survey, 2018.

\section{DISCUSSION}

The study was undertaken to estimate direct costs of hypertension to the sufferer using two hospitals (National hospital and University of Abuja Teaching Hospital) both in Abuja. A survey was undertaken to determine the income level of the participants and amount directly related to the maintenance and treatments which included cost of drugs, consultations, diagnosis and transportations spent annually by individual patients. This was primarily to establish the degree of catastrophic spending and impoverishing tendency of hypertension to the sufferers. It was discovered from the findings that income levels of individuals remained a strong determinant in defining the level of catastrophe and impoverishment faced with individual patients. The average annual total cost attributable to hypertension was N145, 086:12k per patient. About 191 (82 percent) represented respondents who undertook out-of-pocket spending. Hypertension related expenditure was discovered to be catastrophic in 30.5 percent of the least paid respondents.

On enrolment in any government intervention for subsidizing the cost of controlling hypertension, it was established from the findings that only 22.4 percent enrolled for government intervention, specifically National Health Insurance Scheme (NHIS) while about 77.6 percent of the patients were not enrolled for any government intervention in financing the cost of hypertension. This demonstrated that majority of the hypertension patients do not enjoy any government intervention; therefore, culminated to spending out- of- pocket health spending. Therefore, about 9.5 percent of those patients who enrolled enjoyed between N1,000 - N5,000 monthly intervention through national health insurance scheme (NHIS) while about 4.7 percent of the patients enjoyed between N6,000 -N10,000 monthly intervention. About 1.7 percent of the patients claimed to enjoy between N11,000 - N15,000 monthly intervention while about 0.4 percent have between N16,000-N20,000 while only 1.3 percent of the patients have N21,000 and above monthly intervention. Significantly, about 82.3 have no intervention but undertook out-of-pocket spending, which posed significant catastrophic health spending to individual patients living with the disease.

\section{CONCLUSION}

To determine the average annual cost of treating hypertension to the people living with hypertension, the employed survey method and the used instrument of questionnaires which were administered to the sufferers who visited two hospitals (National hospital and University of Abuja Teaching Hospital) both in Abuja. Information on the income level of the participants and amount directly related to the maintenance and treatments which included cost of drugs, consultations, diagnosis and transportations spent annually by individual patients were obtained. The study established that the average annual total cost attributable to hypertension was N145, 086:12k per patient. About 191 ( 82 percent) of the respondents who undertook out-of-pocket spending and hypertension related expenditure was discovered to be catastrophic among 30.5 percent of the least paid respondents.

\section{LIMITATIONS AND FUTURE RECOMMENDATIONS}

To obtain information on indirect burden of hypertension such as productivity loss, disability adjusted life costs still and data on value of statistical life remained daunting as there are no or inadequate data on these variables. Some of the available data are imputed ones which are characterized by inexactness. This remains a major challenge suffered by this study, therefore, limiting the estimate to annual direct average cost of hypertension to the sufferers. The study recommends indirect health financing intervention program that will assist in the reduction of catastrophic effect of hypertension spending on individual through subsidy on hypertensive drugs at pharmaceutical levels. This means that, there should be a bilateral partnership arrangement between governments of various countries and pharmaceutical industries in relation to the regulation of the amount hypertension drugs should be sold. This can be brought to fruition by sharing part of the cost manufacturing of drugs for controlling and treating hypertension by the government so as to enable patients obtains them at lower cost. Enrollment into government scheme (both at national, state and local) level to ease access to healthcare delivery should be emphasized and recommend further studies on these spheres of burden of hypertension.

\section{ACKNOWLEDGEMENTS}

The authors acknowledge National hospital and university of Abuja teaching hospitals both in federal capita territory, Abuja, Nigeria for their supports and cooperation in the course of data gathering for this study. The efforts of the doctors and team of nurses at the cardiology unit of both hospitals highly appreciated.

\section{CONFLICT OF INTEREST}

There was no conflict of interest registered in this study.

\section{REFERENCES}


Abegunde, O.D., \& Stanciole, A. (2006).An Estimation of the Economic Impact of Chronic Non Communicable Diseases in selected countries. Working paper, World Health Organisation ; Retrieved from http://www.who.int/chp.

Adane, E. , Atanafu, A. , \& Aschalew, A. Y.(2020). The Cost of hypertension and Associated factors, university of Gondar Comprehensive Specialised Hospital Nortwest, Ethiopia, 2018. Clinico Economics and Outcomes Research Journal, $12,133-140$.

Bakare, O. Q., Akinyinka, M. R., Goodman, O., Kuyinu, Y. A., Wright, O. K., Adeniran, A., ... \& Osibogun, A. (2016). Antihypertensive use, prescription patterns, and cost of medications in a Teaching Hospital in Lagos, Nigeria. Nigerian journal of clinical practice, 19(5), 668-672.

Bloom, D. E., Cafiero, E. T., McGovern, M. E., Prettner, K., Stanciole, A., Weiss, J., ... \& Rosenberg, L. (2013). The economic impact of non-communicable disease in China and India: estimates, projections, and comparisons (No. w19335). National Bureau of Economic Research.

Chao, S. (2013). Economic Impact of Non-Communicable Diseases in the Caribbean.The World Bank Caribbean Health Financing Conference, November 12-14, 2013.

Dzau, V. J., \& Balatbat, C. A. (2019). Future of Hypertension: The Need for Transformation. Hypertension, 74(3), $450-457$.

Ekman, B. (2007). Catastrophic health payments and health insurance: Some counterintuitive evidence from one low-income country. Health policy, 83(2-3), 304-313.

Eze, C. O., \& Kalu, U. A. (2014). The Prognosis of Acute Stroke in a Tertiary Health Centre in South-East Nigeria. Nigerian Journal of Medicine, 23, 306-310.

Federal Ministry of Health, (1991). National Survey on Non-communicable Diseases in Nigeria.

Gaziano, T. A., Bitton, A., Anand, S., \& Weinstein, M. C. (2009). The global cost of nonoptimal blood pressure. Journal of hypertension, 27(7), 1472-1477.

Ilesanmi, O. S., Ige, O. K., \& Adebiyi, A. O. (2012). The managed hypertensive: the costs of blood pressure control in a Nigerian town. Pan African Medical Journal, 12(1), 1-09.

Jha, P., Nugent, R., Varguet, S., Bloom, D., \& Hum, R.(2013). Chronic Disease Assessment: Third Copenhagen Consensus, Cambridge University press.

Kado, D., Bala, K., \& Dandajeh, M. A. (2016). Pareto Analysis on the Total Quality Management (TQM) Status of the Nigerian Design Firms. ATBU Journal of Environmental Technology, 9(1), 42-57.

Kengne, A. P., Mchiza, Z. J. R., Amoah, A. G. B., \& Mbanya, J. C. (2013). Cardiovascular diseases and diabetes as economic and developmental challenges in Africa. Progress in Cardiovascular Diseases, 56(3), 302-313.

Kirkland, E. B., Heincelman, M., Bishu, K. G., Schumann, S. O., Schreiner, A., Axon, R. N., ... \& Moran, W. P. (2018). Trends in healthcare expenditures among US adults with hypertension: national estimates, 2003-2014. Journal of the American Heart Association, 7(11), 1-09.

Krejcie, R. V., \& Morgan, D. W. (1970). Determining sample size for research activities. Educational and psychological measurement, 30(3), 607-610.

Ndiyo, N.A. (2015). Fundamental of Research in Behavioural Sciences and Humanities. Calaber, Nigeria; Excel, 14 ed. p288.

Charles, C. N. C., Azodo, M. N. M., \& Chuku, C. A. (2014). Causes and pattern of death in a tertiary hospital in south eastern Nigeria. Sahel Medical Journal, 17(3), 102-107.

Lambo, E. (2007). Socio Economic Impact of Non communicable Diseases.

Li, R., Liang, N., Bu, F., \& Hesketh, T. (2020). The Effectiveness of Self-Management of Hypertension in Adults Using Mobile Health: Systematic Review and Meta-Analysis. JMIR mHealth and uHealth, 8(3), 1-16.

Odili, A. N., \& Abatta, E.O.(2015). Blood Pressure Indices, Life Style factors and Anthropometric Correlates of Casual Blood Glucose in rural Nigerian Community.Annal of African Medicine, 1(4),39-45.

Ogah O.,Okpechi, I., Chukwuonye, I.I., Akinyemi J.O., Onwubere B.J.C., Falase,A.O., Stewart, S., \& Sliwa, K. (2012). Blood Pressure, Prevalence of Hypertension and Hypertension Related Complications in Nigerian Africans: A Review. World Journal of Cardiology 2012 December 26; 4(12): 327-340.

Okubadejo, N. U., Ozoh, O. B., Ojo, O. O., Akinkugbe, A. O., Odeniyi, I. A., Adegoke, O., ... \& Agabi, O. P. (2019). Prevalence of hypertension and blood pressure profile amongst urban-dwelling adults in Nigeria: a comparative analysis based on recent guideline recommendations. Clinical hypertension, 25(1), 1-09. 
Oyando, R., Njoroge, M., Nguhiu, P., Kirui, F., Mbui, J., Sigilai, A., ... \& Barasa, E. (2019). Patient costs of hypertension care in public health care facilities in Kenya. The International journal of health planning and management, 34(2), e1166e1178.

Unadike, B.C, Essien I., Akpan, N.A., Peters, E.J., \& Essien O.E.(2013). Profile Outcome of Diabetic admissions at the University of Uyo Teaching Hospital, Uyo.International Journal of Medicine and Medical Sciences 5(6), $286-289$.

Wagstaff, A., \& Doorslaer,V.(2002). Catastrophic and Impoverishment in paying or Healthcare: With Application to Vietnam1993-98. Health Economics, 12(11): 921-934.

Wang, G. , Zhou, X., Zhuo, X., Zhang, P.(2017). Annual Total Expenditures Associated with Hypertension by Diabetes Status in US. Adults. Am J Prev Med 2017; 53(6s2): S182-S189.

Webb, M.C., \& Conrad, D.A.(2012). The Cost of Treating Chronic Non communicable Diseases: Does it Matters? The University of West Indies at St Augustine. 42520. 1-14.

World Health Organization. (2013). A global brief on hypertension: silent killer, global public health crisis: World Health Day 2013 (No. WHO/DCO/WHD/2013.2). World Health Organization.

WHO, (2019). Fact on the prevalence of hypertension. Retrieved from https://www.who.int on April 29, 2020.

Xu, K., Evans, D., Karrin, G., \& Aguilar-Rivera, A. M. (2005). Technical Brief for Policy Makers. Designing health financing systems to reduce catastrophic health expenditure. World Health Organization, Department of Health Systems Financing, Health Financing Policy, 1-4.

Yang, Y., Tang, Y., Jiang, H., Chen, Y., Wan, P., Fan, M., ... \& Lao, M. (2019). 2020 Roadmap on gas-involved photo-and electro-catalysis. Chinese Chemical Letters, 30(12), 2089-2109. 